\title{
Effects of extreme rainfall, typhoons and declaration of marine reserve status on corals beached at Cape d'Aguilar (1998 and 1999)
}

\author{
Brian Morton \\ The Swire Institute of Marine Science and Department of Ecology and Biodiversity, The University of Hong Kong, Hong Kong
}

In the years 1996 and 1997, the pattern of deposition of beached coral heads and pieces onto the shore of Telecom Bay within the Cape d'Aguilar Marine Reserve, Hong Kong suggested that typhoons were a significant natural perturbation. In August 1997, 808 pieces weighing 60,930 g were washed up following passage of Typhoon Victor. 1997 was also Hong Kong's wettest year on record and a survey of the living corals in the reserve in 1998 showed changes in a number of ecological parameters of species richness, composition and diversity but, most noticeably, that the formerly dominant Goniastrea aspera had been superseded by Platygyra sinensis. In 1998 and 1999, this was reflected in the changed proportions of these two beached corals. Dramatically lowered salinities in the bay during July and August 1997 may have effected this change in relative dominance.

Following Typhoon Dan in October 1998, 342 pieces of corals weighing 75,600 g were collected. The 1996 and 1997 pattern seemed to be repeating itself. 1999 was a bad year for severe tropical storms and typhoons in Hong Kong, seven being reported upon. Yet, after each one only 12,490 g (Typhoon Leo), $3390 \mathrm{~g}$ (Typhoon Maggie), $3550 \mathrm{~g}$ (Severe Tropical Storm: no-name), $55 \mathrm{~g}$ (Typhoon Sam), $4500 \mathrm{~g}$ (Typhoon York and Typhoon Cam) and $3160 \mathrm{~g}$ (Typhoon Dan) were washed up. That is, the seven tropical depressions deposited about 27,640 g coral, approximately the same amount as only Typhoon Sally in 1996 (25,000 g) and Tropical Storm Penny and Typhoon Babs in 1998 (24,574 g) and less than half that of Typhoon Victor in 1997 (60,000 g).

In July 1996, Cape d'Aguilar was declared a marine reserve, fishing banned in its 18 hectares of sea and ghost nets removed. The fishing ban seems to be halting the dislodgement of corals and they are thus not now being beached by typhoons.

\section{INTRODUCTION}

Hong Kong experiences a monsoonal climate with tropical storms and typhoons affecting it each summer. Every month for a period of two years from 1 January 1996 to 31 December 1998 inclusive, Clark \& Morton (1999) collected all the heads and pieces of scleractinian corals that washed up on a shore, Telecom Bay, within Hong Kong's Cape d'Aguilar Marine Reserve. They also identified and counted the numbers of molluscan borers occurring in each piece. It was concluded that basal borers, in particular, weaken colony attachment, resulting in dislodgement during and beaching after storms. In arriving at this conclusion, Clark \& Morton (1999) had reviewed the literature regarding coral bioerosion and, in particular, that pertaining to the effects of tropical storm and hurricane-generated waves on the geomorphology of reefs (Maragos et al., 1973; Stoddart, 1974; Hernandez-Avila et al., 1977; Bradbury \& Young, 1981; Woodley et al., 1981; Fenner, 1991; Rogers et al., 1991; Blair et al., 1994).

Dollar (1982) described physical disturbance from waves as the most significant factor determining the structure of reef communities in Hawaii, with severe, infrequent storms causing massive mortality to all coral species thereby obliterating the former pattern of community structure. Few quantitative studies of hurricane-produced coral damage have, however, been reported upon (Woodley et al., 1981). Hurricanes, depending on their intensity and proximity to a reef, have been shown to damage coral communities to varying degrees. Relatively minor patchy damage was recorded after the strongest hurricane (Gilbert) on record in the western hemisphere passed over Cozumel, Mexico (Fenner, 1991). Minor damage was also recorded for Hurricanes David, Frederic (1979) and Hugo (1989) by Rodgers et al. (1982, 1991). Severe damage has also been recorded (Highsmith et al., 1980). Woodley et al. (1981) reported that waves produced by Hurricane Allen, and the dislodged material they carried, devastated the shallow reefs in Discovery Bay, Jamaica. Stoddart (1974) studied the effects of Hurricane Hattie in Belize and Blair et al. (1994) studied Hurricane Andrew's effects in Florida. Both showed that damage was patchy, being severe in some areas and moderate to mild in others. Glynn et al. (1964) and Woodley et al. (1981) reported that wave surge during hurricanes was greater in shallow than deep water, thereby, generally, producing greater damage in the former depths, with branching corals tending to suffer more destruction than both encrusting and massive species.

Clark \& Morton (1999) quantified live coral cover within Telecom Bay to obtain a picture of the importance of beaching in relation to the total mass of corals (both living and dead) within the bay. Clark (1998) had surveyed 
the hermatypic corals within the marine reserve in 1995 and 1997 and noted that during the summers of these years there was partial bleaching and the death of a number of colonies of Porites lobata (Clark, 1995). Clark (2000) resurveyed the corals of Telecom Bay in April 1998 and noted that some corals, e.g. Montipora informis, Acropora pruinosa, Coscinarea columna, Hydnophora exesa, Turbinaria peltata and Oulastrea crispata, had been lost from sites they were recorded from in 1995 and 1997 and there had been a marked reduction in the number of coral species and species diversity and that this was most marked at her Site D seaward of Telecom Bay where the beached corals had been collected from in 1996 and 1997 (Clark \& Morton, 1999). At Site D, moreover, there was a decrease in colony numbers of Favites abdita, Montipora informis, Favia speciosa, Porites lobata and, importantly, Platygyra sinensis and an overall increase in the numbers of Goniastrea aspera. Severe climatological events occurred in 1997, 1998 and 1999 in Hong Kong but, all the while, the monthly collections of beached coral heads from Telecom Bay continued.

The results of this further two years of collection are herein analysed in relation to: (i) the background picture of a changing coral community structure in the marine reserve (Clark 2000); (ii) the severe climatological events recorded in 1997, 1998 and 1999; (iii) the incidence of basally-boring Lithophaga lima in the beached coral pieces and heads; and (iv) the conferment of marine reserve status upon Cape d'Aguilar in July 1996. That is, in 1996 and 1997, severe climatological events, notably typhoons, were concluded to cause coral beaching. Would they also in 1998 and 1999 following further severe typhoon events, especially, in the latter year? Finally, would enforcement in late 1997 of the Marine Parks Ordinance that banned fishing in the Cape d'Aguilar Marine Reserve affect coral beaching?

\section{MATERIALS AND METHODS}

For two years, from 1 January 1998 to 31 December 1999, the $\sim 400 \mathrm{~m}^{2}$ beach at Telecom Bay [for descriptions of the site see Morton \& Harper (1995, figure 3) and Clark \& Morton (1999, figure 1)] was searched, usually around the 23-24 of each month and all pieces of beached corals collected. Additional collections were made typically one day after any tropical depression passed either over or close to Hong Kong and which necessitated the hoisting of a signal $>$ no. 3. All coral pieces were identified to species and, in each one, the numbers of basal holes determined to have been made by Lithophaga (most often L. lima) counted.

The records of the Hong Kong Observatory (19981999) provide a picture of weather conditions over the two year period and in comparison with 1996 and 1997 (Royal Observatory, Hong Kong, 1996, 1997). Weekly records of salinity (psu) and suspended solids $\left(\mathrm{mgl}^{-1}\right)$ for Telecom Bay were also consulted to identify extreme events. The Hong Kong Observatory categorizes tropical depressions as follows:

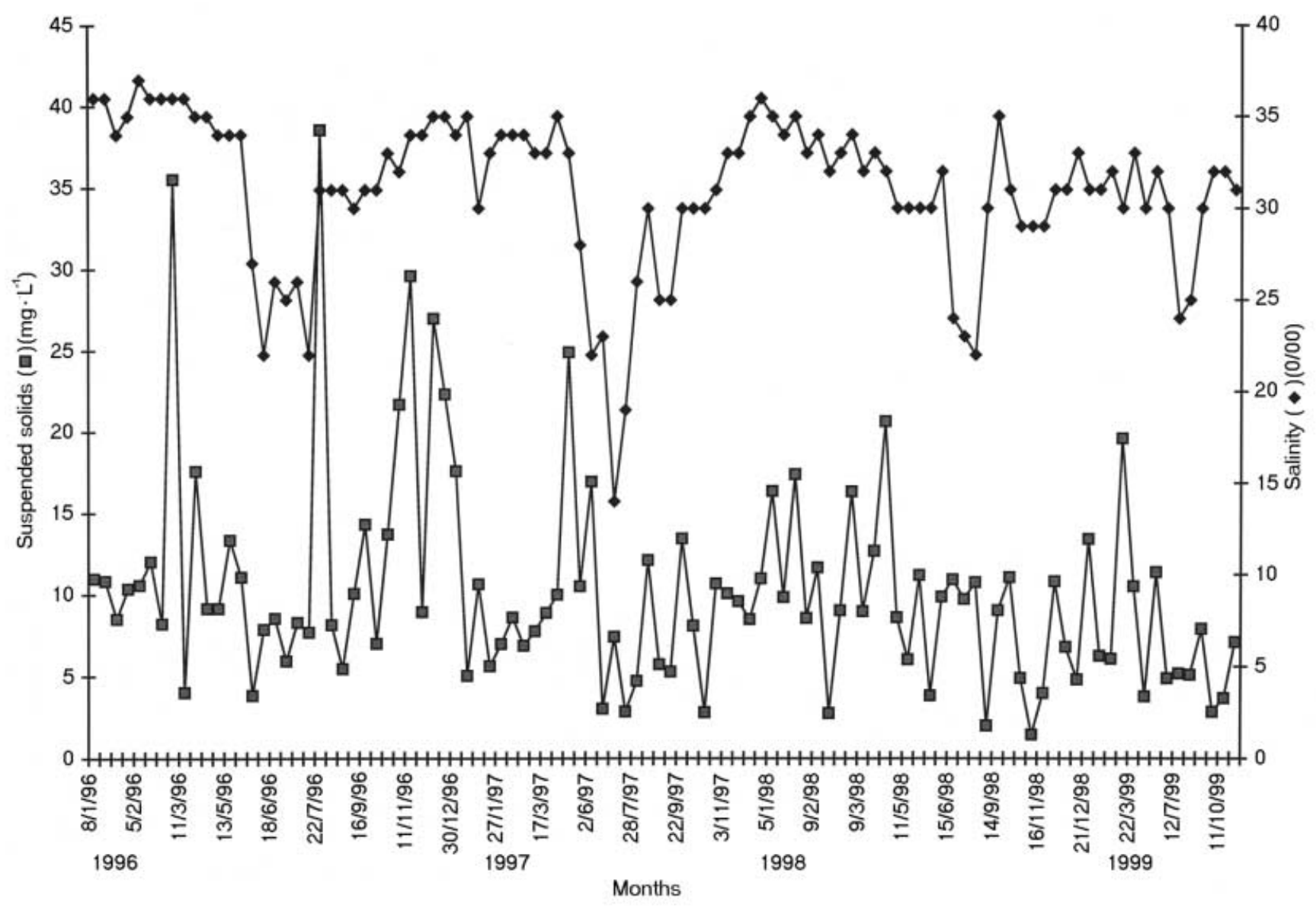

Figure 1. Surface salinity and suspended solids data recorded from Telecom Bay, Cape d'Aguilar Marine Reserve over the period 1 January 1996 to 31 December 1999 inclusive. 
(i) A tropical depression has maximum sustained winds of $<63 \mathrm{~km} \mathrm{~h}^{-1}$;

(ii) A tropical storm has maximum sustained winds in the range of $63-87 \mathrm{~km} \mathrm{~h}^{-1}$;

(iii) A severe tropical storm has maximum sustained winds in the range of $88-117 \mathrm{~km} \mathrm{~h}^{-1}$;

(iv) A typhoon has maximum sustained winds of $>118 \mathrm{~km} \mathrm{~h}^{-1}$.

\section{RESULTS}

\section{Hong Kong's climate}

Located $120 \mathrm{~km}$ within the Tropic of Cancer, Hong Kong is nevertheless sub-tropical with a climate created by the interplay of the north-east and south-east monsoons in winter and summer, respectively (Morton \& Morton, 1983). Hong Kong's winters are thus cold and dry, summers hot and wet and spring and autumn periods of transition. Normal mean air temperature ranges between $15.8^{\circ} \mathrm{C}$ in January to $28.8^{\circ} \mathrm{C}$ in July and is matched approximately one month later by sea temperature, i.e. $16.9^{\circ} \mathrm{C}$ in February and $27.5^{\circ} \mathrm{C}$ in September. Hong Kong's rainfall is highly seasonal with a mean normal total (1961-1990) of $2214 \mathrm{~mm}$ (Table 1). Least rain falls in January (23.4 mm), most in August (391 mm). Some 53 species of corals survive this temperature range and periodic severe surface dilution by summer rains in Hong Kong.

Throughout the year, mean normal wind direction is from the east $\left(090^{\circ}\right)$ with a mean speed of $11.0 \mathrm{~km} \mathrm{~h}^{-1}$ (range: 9.4 in August, south-east monsoon and 12.6 in March, north-east monsoon). Mean wave heights are thus higher in winter by about $1 \mathrm{~m}$ in comparison with summer (Apps \& Chen, 1973). With the passage of tropical depressions either over or close to Hong Kong, however, mean maximum wind gusts of $259 \mathrm{~km} \mathrm{~h}^{-1}$ are recorded in September, as compared to only $96 \mathrm{~km} \mathrm{~h}^{-1}$ in January.

\section{Climate at Cape d'Aguilar (1996-1999)}

This study is not concerned with either air or sea temperature as, overall, the range of both parameters will not generally affect Hong Kong's subtidal corals except in the special cases of intertidal rock pools (Clark, 1995). Coral bleaching has been recorded to occur only when low spring tides coincide with greatly reduced, wind-chill temperatures, as for example at Hoi Ha Wan (Cope \& Morton, 1988). The important parameters in relation to this study are (i) rainfall (and its influence upon sea surface salinity) and (ii) wind speed and direction.

Hong Kong has a mean normal total rainfall of $2214 \mathrm{~mm} \mathrm{y}^{-1}$ (Table 1). For 1996-1999, maximum rainfall values ranged around means of $2248 \mathrm{~mm} \mathrm{(1999)}$ to $2992 \mathrm{~mm}$ (1998). Maximum rainfall in 1997, however, was $3820 \mathrm{~m}$, a record $72 \%$ more than normal. Total mean rainfall values for Cape d'Aguilar were about $1484 \mathrm{~mm}$ in 1996, but this rose to $2392 \mathrm{mmy}^{-1}$ in 1997 and then fell to 1647 and $1578 \mathrm{mmy}^{-1}$ in 1998 and 1999, respectively. At Cape d'Aguilar in 1997, most rain fell in July $(602 \mathrm{~mm})$ and August $(665 \mathrm{~mm})$. Such figures represent $53 \%$ of what would fall in total during a normal year. 1997 was thus an all-time record rainfall year for Hong Kong and typically dry Cape d'Aguilar was particularly badly affected.

In 1996-1999 mean wind direction was, typically, from the south-west in summer $\left(210^{\circ}-240^{\circ}\right.$ from June to August) and from the east for most of the rest of the year $\left(20^{\circ}-100^{\circ}\right.$ from October to the following May). All four years showed the same general pattern. Mean annual wind speeds also ranged between 6.4 (1997) to $7.2 \mathrm{~km} \mathrm{~h}^{-1}$ (1996) and were relatively stable at between $4.6-8.7 \mathrm{~km} \mathrm{~h}^{-1}$ (Table 2).

Table 1. Normal values for rainfall for Hong Kong compared with Cape d'Aguilar for 1996-1999 and direction and mean wind speeds also for 1996-1999 (Source: Royal Observatory Hong Kong, 1996, 1997; Hong Kong Observatory, 1998, 1999).

\begin{tabular}{|c|c|c|c|c|c|c|c|c|c|c|c|c|c|}
\hline \multirow[b]{2}{*}{ Month } & \multirow{2}{*}{$\begin{array}{l}\text { Normal } \\
\text { rainfall for } \\
\text { Hong Kong } \\
(1961-1990) \\
(\mathrm{mm})\end{array}$} & \multicolumn{4}{|c|}{ Rainfall at Cape d'Aguilar } & \multicolumn{2}{|c|}{1996} & \multirow{2}{*}{\multicolumn{2}{|c|}{1997}} & \multirow{2}{*}{\multicolumn{2}{|c|}{1998}} & \multirow{2}{*}{\multicolumn{2}{|c|}{1999}} \\
\hline & & 1996 & 1997 & 1998 & 1999 & Direction & $\begin{array}{c}\text { Mean wind } \\
\text { speed } \\
\left(\mathrm{km} \mathrm{h}^{-1}\right)\end{array}$ & & & & & & \\
\hline $\mathrm{J}$ & 23.4 & 0 & 29.0 & 39.5 & 2.0 & 070 & 7.5 & 070 & 7.4 & 060 & 8.0 & 060 & 6.9 \\
\hline $\mathrm{F}$ & 48.0 & 0 & 143.5 & 78.5 & 0 & 070 & 7.8 & 070 & 8.4 & 020 & 6.8 & 070 & 6.9 \\
\hline M & 66.9 & 0 & 16.5 & 23.0 & 10.0 & 070 & 7.1 & 060 & 5.9 & 050 & 7.2 & 070 & 7.0 \\
\hline A & 161.5 & 81.0 & 79.0 & 142.5 & 108.0 & 070 & 8.5 & 070 & 6.1 & 060 & 5.0 & 070 & 7.6 \\
\hline M & 316.7 & 365.5 & 344.5 & 272.0 & 136.5 & 070 & 5.8 & 070 & 5.8 & 100 & 5.2 & 070 & 7.0 \\
\hline $\mathrm{J}$ & 376.0 & 15.5 & 127.5 & 435.0 & 116.0 & 220 & 5.8 & 210 & 5.8 & 210 & 6.9 & 190 & 5.6 \\
\hline $\mathrm{J}$ & 323.5 & 130.0 & 602.0 & 260.0 & 167.0 & 230 & 6.8 & 110 & 5.3 & 230 & 6.4 & 220 & 5.8 \\
\hline A & 391.4 & 369.5 & 665.0 & 149.0 & 675.0 & 240 & 6.6 & 230 & 7.2 & 230 & 4.6 & 220 & 5.5 \\
\hline $\mathrm{S}$ & 299.7 & 451.5 & 334.0 & 143.0 & 267.07 & 090 & 7.5 & 090 & 6.1 & 080 & 6.5 & 010 & 6.0 \\
\hline $\mathrm{O}$ & 144.8 & 67.0 & 37.5 & 97.0 & 58.5 & 080 & 6.9 & 090 & 5.4 & 080 & 8.4 & 080 & 7.9 \\
\hline $\mathrm{N}$ & 35.1 & 3.5 & 2.0 & 0 & 11.5 & 080 & 8.7 & 090 & 6.4 & 070 & 7.3 & 070 & 8.1 \\
\hline $\mathrm{D}$ & 27.3 & 0 & 11.5 & 7.5 & 26.0 & 070 & 6.9 & 060 & 7.3 & 010 & 7.5 & 010 & 7.8 \\
\hline $\begin{array}{l}\text { Total for Cape } \\
\text { d'Aguilar }\end{array}$ & & 1483.5 & 2392.0 & 1647.0 & 1577.5 & 070 & 7.2 & 070 & 6.4 & 070 & 6.8 & 070 & 6.9 \\
\hline $\begin{array}{l}\text { Total/normal } \\
\text { (Hong Kong) }\end{array}$ & 2214.3 & 2269.5 & 3819.5 & 2992.0 & 2248.0 & & & & & & & & \\
\hline
\end{tabular}




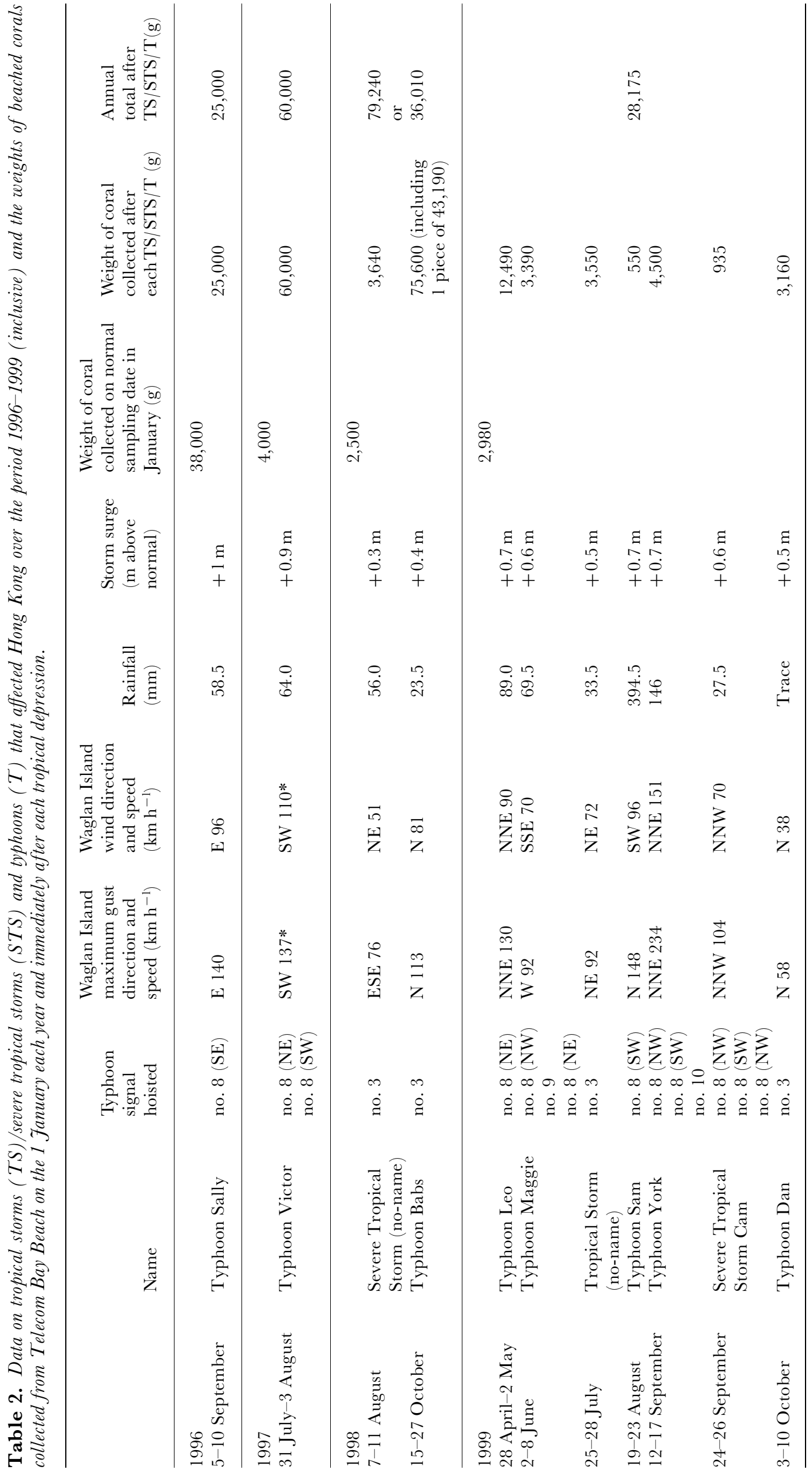




\section{Tropical storms/severe tropical storms/typhoons}

In September 1996, only Typhoon Sally passed close to Hong Kong causing Typhoon Signal no. 8 (SE) to be hoisted and with maximum gusts of $140 \mathrm{~km} \mathrm{~h}^{-1}$ from the east (Table 2). Wave heights were $+1 \mathrm{~m}$ higher than normal and rainfall was minimal at $58.5 \mathrm{~mm}$. At Waglan Island (closest recording station to Cape d'Aguilar at $4.9 \mathrm{~km}$ ), a mean wind speed and maximum gusts of 96 and $140 \mathrm{~km} \mathrm{~h}^{-1}$ were recorded, respectively.

In 1997, only Typhoon Victor passed over Hong Kong causing Typhoon Signal no. 8 (NE and later SE) to be hoisted and with maximum wind gusts of $137 \mathrm{~km} \mathrm{~h}^{-1}$, unusually first from the north-east and then from the south-west (Table 2). At Waglan Island, a mean wind speed and maximum gusts of 110 and $137 \mathrm{~km} \mathrm{~h}^{-1}$ were recorded, respectively.

In 1998, Severe Tropical Storm Penny and Typhoon Babs passed close to Hong Kong in August and October, respectively, but as only Typhoon Signal no. 3 was hoisted for both, their effects were minimal in terms of wind speed, i.e. 76 and $113 \mathrm{~km} \mathrm{~h}^{-1}$ from the east-south-east and north, respectively (Table 2). At Waglan Island, mean wind speeds ( NE 51 and $\mathrm{N} 81 \mathrm{~km} \mathrm{~h}^{-1}$ ) and maximum gusts (ESE and $\mathrm{N} 113 \mathrm{~km} \mathrm{~h}^{-1}$ ) were similarly low.

In 1999, seven tropical storms, severe tropical storms and typhoons passed close to Hong Kong necessitating the hoisting of signals $>$ no. 3 on six and $>$ no. 8 on two occasions, respectively. Wind speeds for Typhoon Maggie in June were low $\left(92 \mathrm{~km} \mathrm{~h}^{-1}\right)$ and from the west. Wind speeds for the others ranged from $92 \mathrm{~km} \mathrm{~h}^{-1}$ (Severe Tropical Storm no-name) in July to $234 \mathrm{~km} \mathrm{~h}^{-1}$ (Typhoon York) in September. At Waglan Island, the winds were from the north on all occasions, except for Typhoons Maggie and Sam, i.e. from the south-south-east and southwest, respectively, but with low wind speeds. Over the four years, therefore, only Typhoon Victor, in 1998, was unusual in that it arrived, generally, with strong winds $\left(110 \mathrm{~km} \mathrm{~h}^{-1}\right)$ from the south-west and thus, directly affected Cape d'Aguilar which is usually protected from the main typhoon direction in normal years. For the typhoon events at Cape d'Aguilar between 1996 and 1999, therefore, rainfall ranged from trace (Typhoon Dan) to $395 \mathrm{~mm}$ (Typhoon Sam) and storm surges (wave heights above normal) ranged from $+0.3 \mathrm{~m}$ (Severe Tropical Storm no-name in 1998) to $+1 \mathrm{~m}$ (Typhoon Sally in 1996).

\section{Suspended solids and salinity at Cape d'Aguilar (1996-1999)}

Salinity and suspended solids data for Telecom Bay are presented in Figure 1 for the period 1 January 1996 to 31 December 1999 inclusive. As noted by Clark (2000), peaks in suspended solid levels were recorded in March 1996, July 1996 and November and December 1996. These peaks were related by Clark (2000) to construction work being carried out around the bay and terrigenous run-off into it. Changes to the coral communities in Telecom Bay, notably her Site D, were also ascribed in part to this by Clark (2000) but turbidity levels declined progressively subsequently (Figure 1).

June and July 1997, a major El Niño Year (Freeland et al., 1999), were the wettest on record for Hong Kong resulting in a minimum recorded salinity in Telecom Bay of $<\sim 14$ psu in July 1997 when rainfall was the highest on record (Table 1). Interestingly, this was not accompanied by an increase in sediment levels in the bay, construction work having ceased and slopes stabilized a year earlier. Heavy rain also characterized June 1998 (Table 1) but salinity only fell to $\sim 20 \mathrm{psu}$.

One severe tropical storm (Severe Tropical Storm Penny) and one typhoon (Typhoon Babs) affected Hong Kong in 1998 from 7-11 August and 15-27 October, respectively. The picture in 1999 was, however, different with seven tropical storms (2) and typhoons (5) affecting Hong Kong from 28 April-2 May (Typhoon Leo: signal no. 8), 2-8 June (Typhoon Maggie; no. 8), 19-23 August (Typhoon Sam; no. 8), 12-17 September (Typhoon York: no. 8), 24-26 September (Typhoon Cam: no. 8). For Typhoon York, wind speeds gusted up to $130 \mathrm{~km} \mathrm{~h}^{-1}$. Two smaller typhoons also affected Hong Kong in 1999; i.e. a tropical storm (no-name) on 25-28 July (no. 3) and Typhoon Dan from 3-10 October (no. 3). Such storm events and prevailing monthly wind speeds and directions are recorded for this survey period, 1998 and 1999, and compared with data for 1996 and 1997 (Table 2). Mean wind speeds were actually low in 1998 and 1999, as compared to 1996 and 1997, so that in this study, specific tropical storm and typhoon events were of more interest and significance in relation to the beaching of corals in Telecom Bay.

\section{Total numbers of pieces of corals collected from Telecom Bay Beach each month}

Figure 2 shows the total numbers of heads and pieces of corals collected from Telecom Bay Beach each month for the period January 1998 to December 1999. Most (342) were collected in October 1998. Prior to this, however, numbers had fallen from 65 in January 1998 to 19 in July 1998, then risen slightly in August 1998 to 163 and fallen again in September 1998 (54). After October 1998, numbers fell to a minimum in April 1999 (35), increased over the summer months of May (114), June (91) and July (113), fell to 25 in August, peaked in September (145) and declined to 8 in December 1999. Figure 2 also identifies the numbers of beached corals in terms of species.

\section{Total weights of corals collected from Telecom Bay Beach each month}

The weights of corals collected each month were low and usually $<20,000 \mathrm{~g}$ (Figure 3). The exception to this was October 1998 when a single 43,190 g head of Platygyra sinensis was washed up onto the beach giving a monthly sample weight of 75,600 g. Despite this, however, October 1998 would still have been higher than any other month $(22,410 \mathrm{~g})$, followed by November 1998; but other than these two, and May 1999, weights were all $<500$ g even though collections were often made more than twice a month at the time of typhoon events.

\section{Total numbers of pieces of corals collected from Telecom Bay Beach after typhoons}

In addition to the regular monthly collections, beached corals were also collected as soon as feasible after any severe tropical storm or typhoon event. These collections 


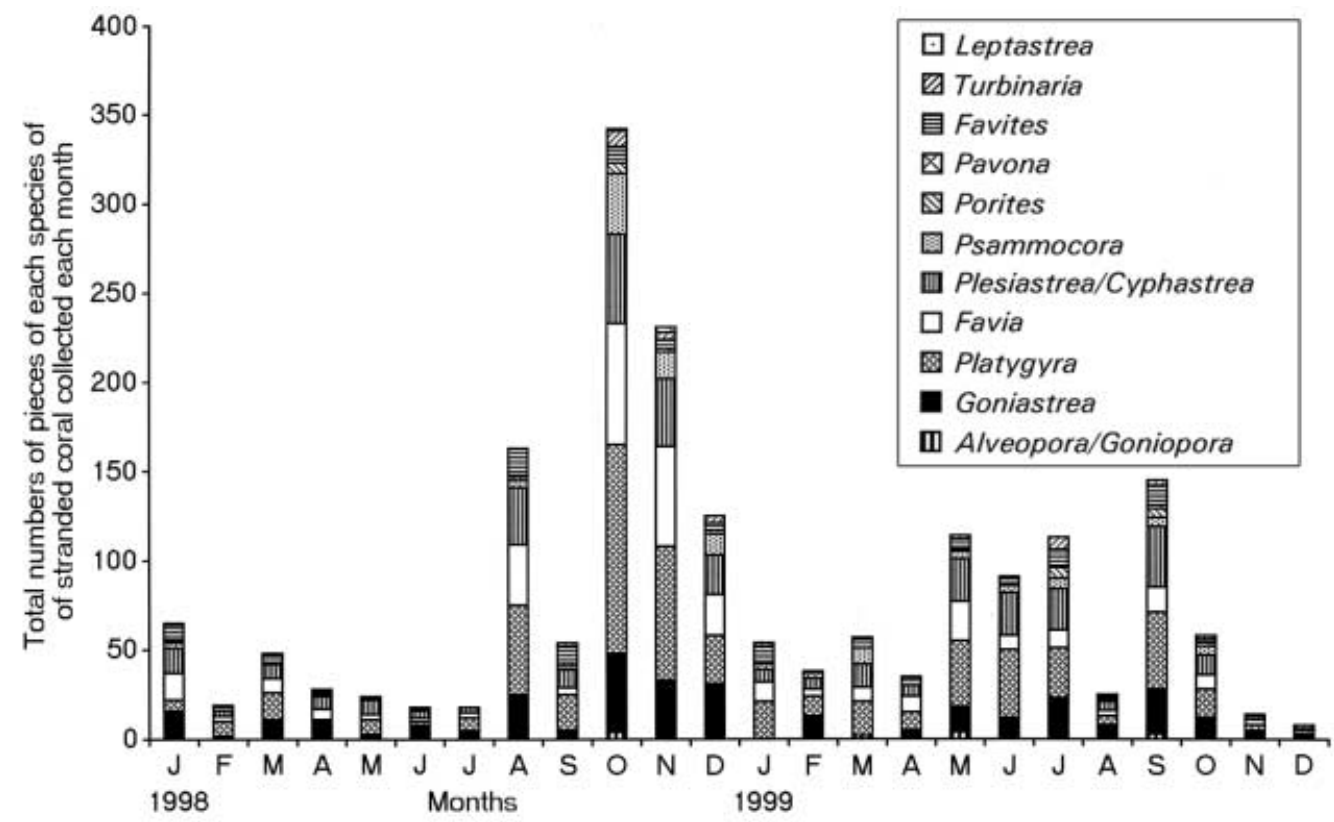

Figure 2. The total monthly numbers of 11 species of corals collected from the shores of Telecom Bay over the period from 1 January 1998 to 31 December 1999 inclusive.

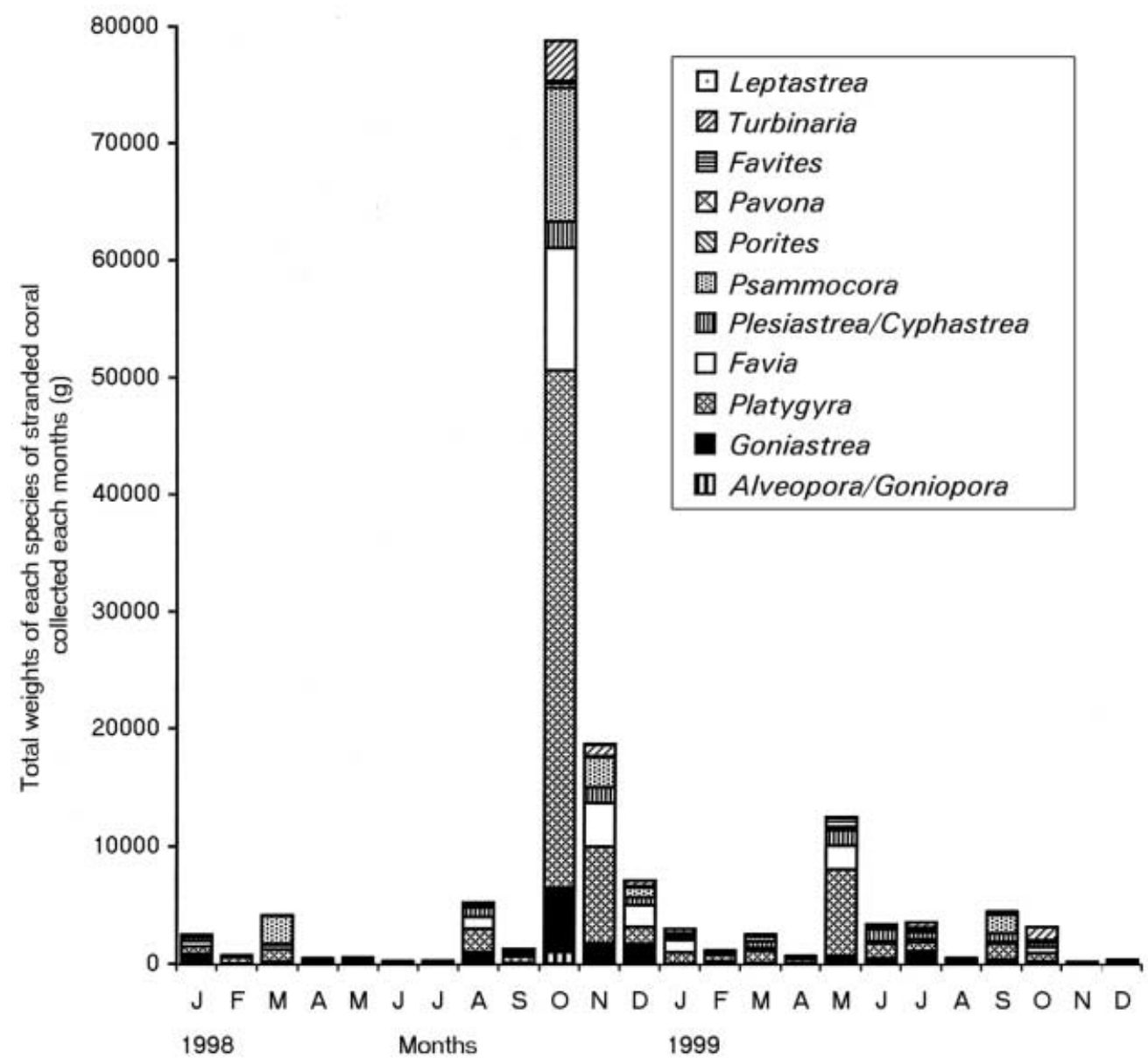

Figure 3. The total monthly weights of 11 species of corals collected from the shores of Telecom Bay over the period from 1 January 1998 to 31 December 1999 inclusive.

are identified in Figure 4. As noted earlier, numbers of regularly-collected corals declined generally from 65 on 24 January 1998 until after Severe Tropical Storm Penny on 10 August when 125 pieces were collected. Over 250 pieces were collected after Typhoon Babs on the 27 October and an almost equally high number on the regular sampling date of 21 November. Figure 5 shows the numbers of coral heads and pieces collected from Telecom Bay Beach prior 


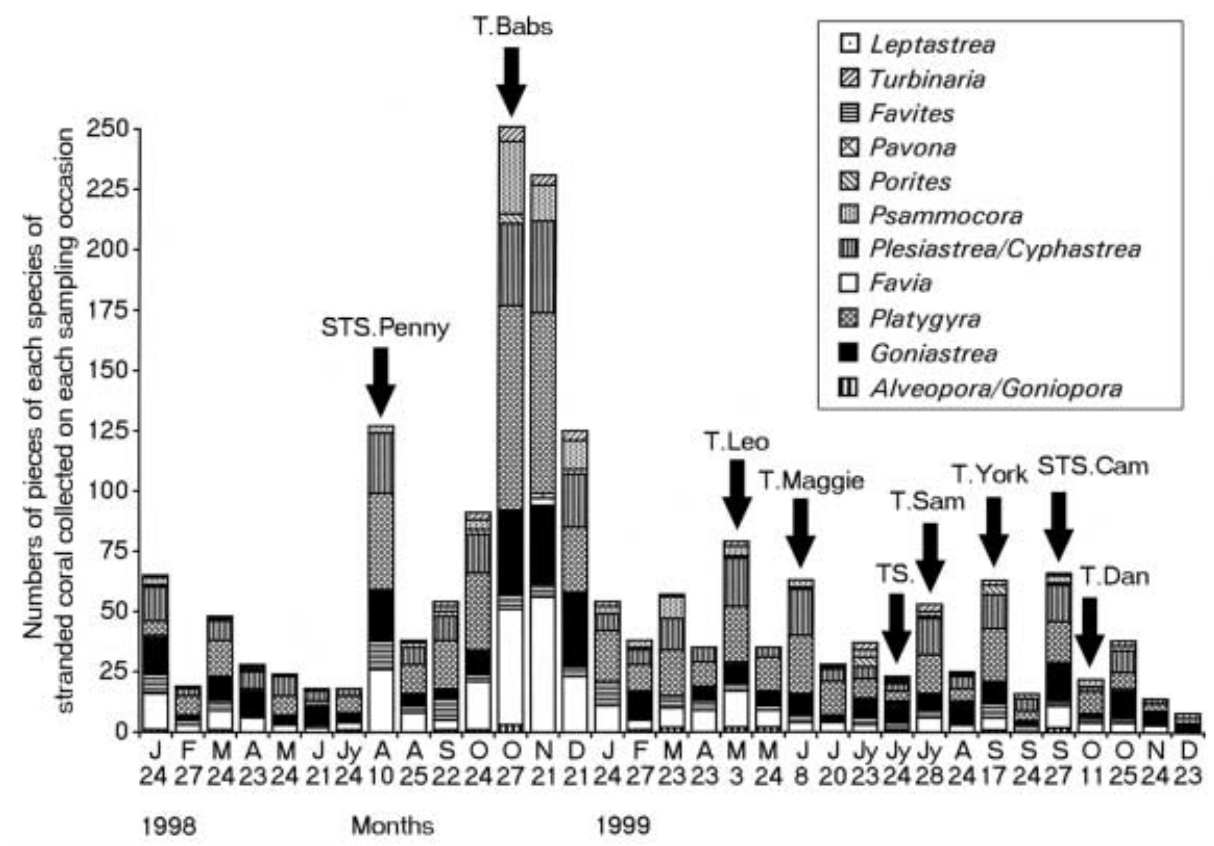

Figure 4. The total numbers of 11 species of corals collected from the shores of Telecom Bay over the period 1 January 1998 to 31 December 1999, inclusive. Note that this figure is different from Figure 3 in that all sample numbers, including those taken after a tropical storm or typhoon (arrow) are included.

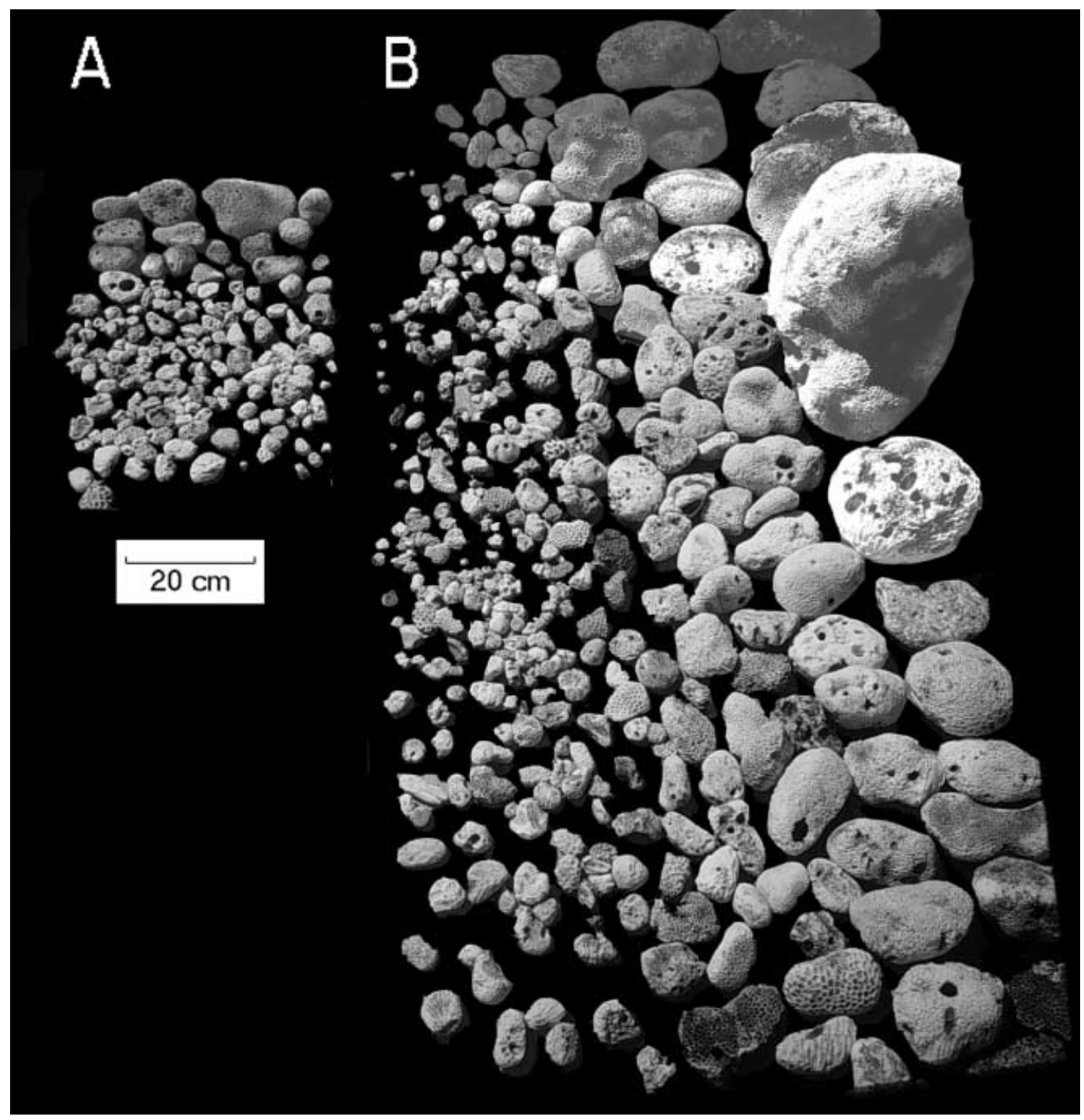

Figure 5. Photographs of the beached corals collected from Telecom Bay on (A), 24 October 1998 prior to Typhoon Babs and (B), on 27 October after passage of the typhoon. 
to Typhoon Babs on (A) 24 October and (B) after it on 27 October 1998. Thereafter, numbers of corals collected declined throughout 1999, albeit with small increases following each of the seven tropical storm or typhoon events of that year, but numbers collected were always $<80$ pieces.

\section{Total weights of pieces of corals collected from Telecom Bay Beach after typhoons}

The weights of pieces of corals collected from Telecom Bay Beach not only at the time of each regular monthly sampling day from January 1998 to December 1999 but also at additional times after each severe tropical storm or typhoon event are shown in Figure 6. As noted above, the large amount of 75,600 $\mathrm{g}$ collected after Typhoon Babs on 27 October 1998 was mostly attributed to one large head of 43,190 g. Subsequently, however, and except for 3 May 1999 (Typhoon Leo) when 12,490 g was collected, all other typhoon samples were little different from the monthly ones and all of low weights.

Figure 7 analyses in more detail the weights of coral samples collected from Telecom Bay before, immediately and one collecting month after each tropical storm event during 1998 and 1999. Prior to Severe Tropical Storm Penny from 19-23 August 1998, $260 \mathrm{~g}$ of corals was collected from Telecom Bay Beach on 24 July. Immediately after the storm hit Hong Kong on 10 August, $3640 \mathrm{~g}$ was collected and on the regular sampling day, i.e. 25 August, $1560 \mathrm{~g}$ was obtained (Figure 7A). Prior to Typhoon Babs on 24 October $1998,1250 \mathrm{~g}$ of corals was collected on 22 September. On the typhoon day itself only $3210 \mathrm{~g}$ was collected but three days later on 27 October, 75,600 $\mathrm{g}$ was obtained, including one piece of Platygyra of 43,190 g (see above). One and two months later, the weights of corals collected had fallen to $18,670 \mathrm{~g}$ (November) and $7070 \mathrm{~g}$ (December), respectively (Figure 7B).

Prior to Typhoon Leo from 28 April-3 May 1999, only $700 \mathrm{~g}$ of corals was collected from Telecom Bay on the regular sampling day of 24 April. Post Typhoon Leo, $11,170 \mathrm{~g}$ was collected and on the regular sampling day of 24 May amounts had fallen to $1320 \mathrm{~g}$ (Figure 7C). Prior to Typhoon Maggie from 2-8 June 1999, on the regular sampling day of 24 May, $1320 \mathrm{~g}$ of corals was collected. After the typhoon, on 8 June 1999, $2540 \mathrm{~g}$ was collected whereas on 20 June only $930 \mathrm{~g}$ was collected (Figure 7D). On 23 July 1999 after a tropical storm (no-name) passed over Hong Kong on 21-22 July, $1170 \mathrm{~g}$ of corals was collected. On the next regular sampling day (24 July), $610 \mathrm{~g}$ was collected. After Typhoon Sam from 25-28 July $1999,1770 \mathrm{~g}$ of coral was collected from Telecom Bay Beach but one month later, on 24 August, only $550 \mathrm{~g}$ was collected (Figure 7E). On 17 September 1999, after Typhoon York from 12-17 September 1999, 1200g of coral was collected. Seven days later, however, on the regular sampling date of 24 September, $1690 \mathrm{~g}$ was collected (Figure 7F). On 27 September after Severe Tropical Storm Cam (24-26 September 1999), $1610 \mathrm{~g}$ of coral was collected. A further $1160 \mathrm{~g}$ was collected on 11 October after Typhoon Dan (3-10 October 1999) and on the regular sampling date of 25 October 1999, $2000 \mathrm{~g}$ of coral was collected (Figure 7G).

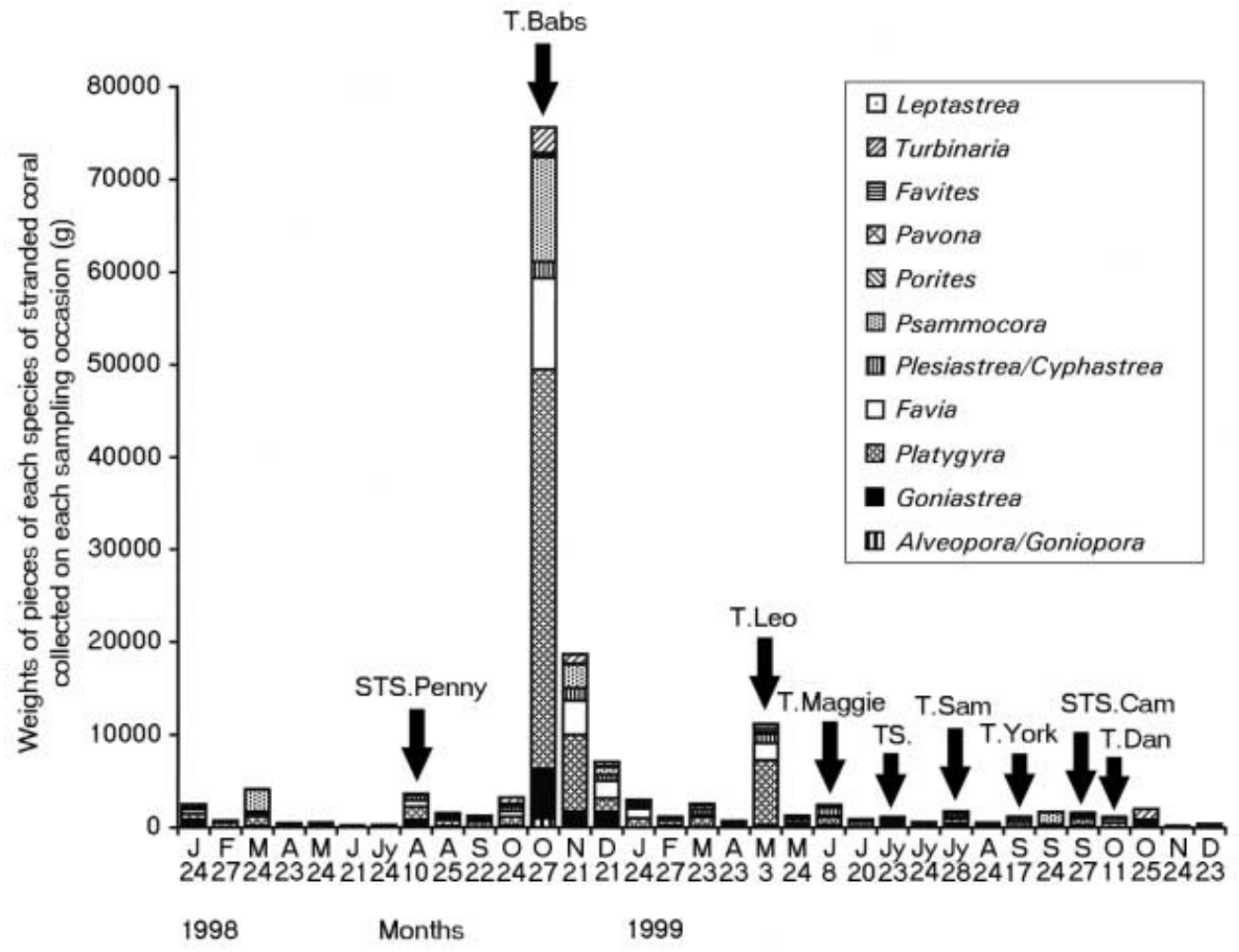

Figure 6. The total weights of 11 species of corals collected from the shores of Telecom Bay over the period from 1 January 1998 to 31 December 1999 inclusive. Note that this figure is different from Figure 3 in that all sample weights, including those taken after a tropical storm or typhoon (arrow) are included. 
A Before and after Severe Tropical Storm Penny (No.3) on August 1998

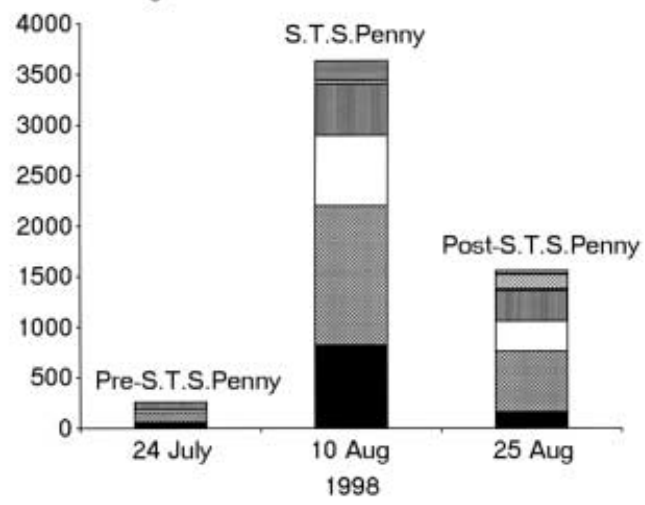

B Before and after Typhoon Babs (No.3) on 24 October 1998 with two subsequent months in data.

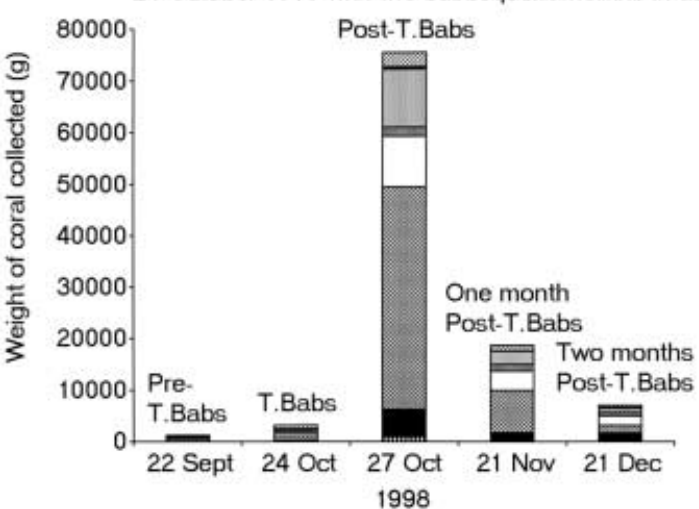

C Before and after Typhoon Leo (No.8) on 3 May 1999

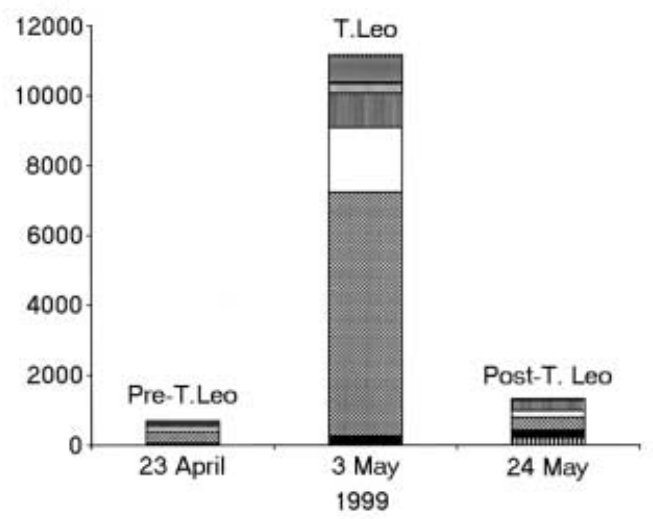

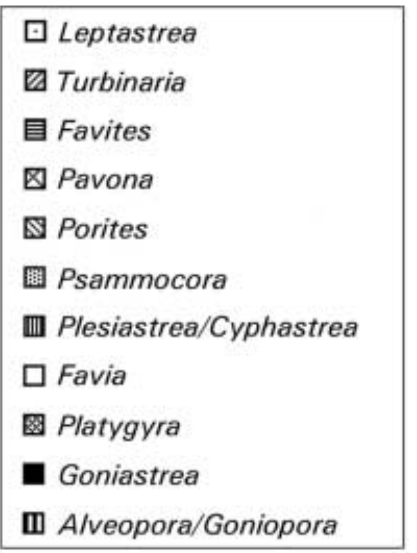

Before and after Typhoon Maggie (No.9) on 8 June 1999

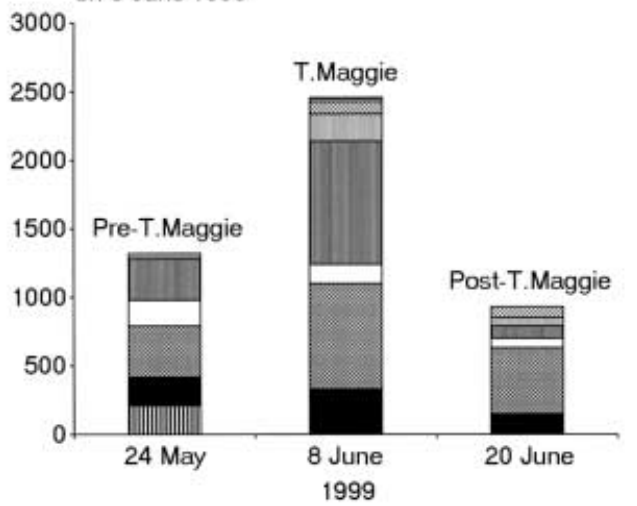

E Before and after Tropical Storm (No name)(No.3) on 23 July 1999 and Typhoon Sam (No.10) on 28 July 1999

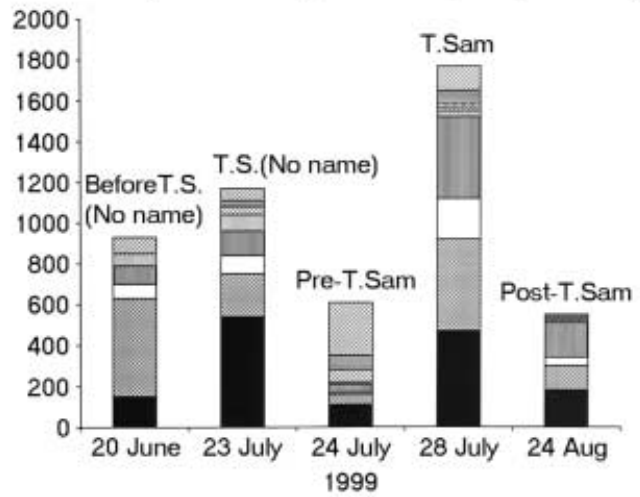

F Before and after Typhoon York (No.10) on 17 September 1999

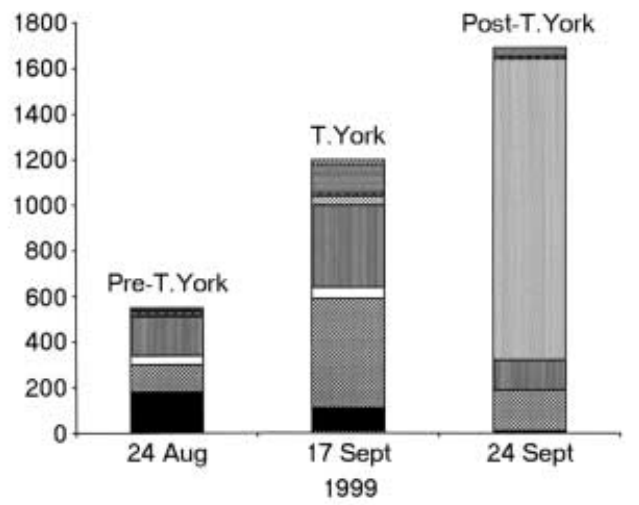

G Before and after Severe Tropical Storm Cam (No.8) on 27 September and Typhoon Dan (No.3) on 11 October 1999

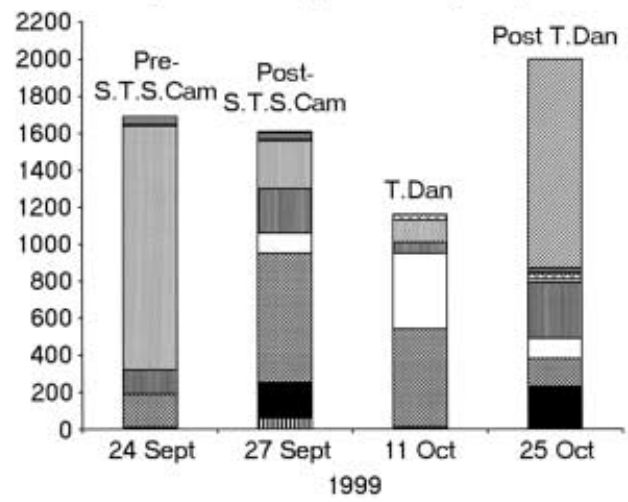

Figure 7. The weights of corals collected from Telecom Bay before, immediately after and one month after severe tropical storm or typhoon events in 1998 and 1999. 


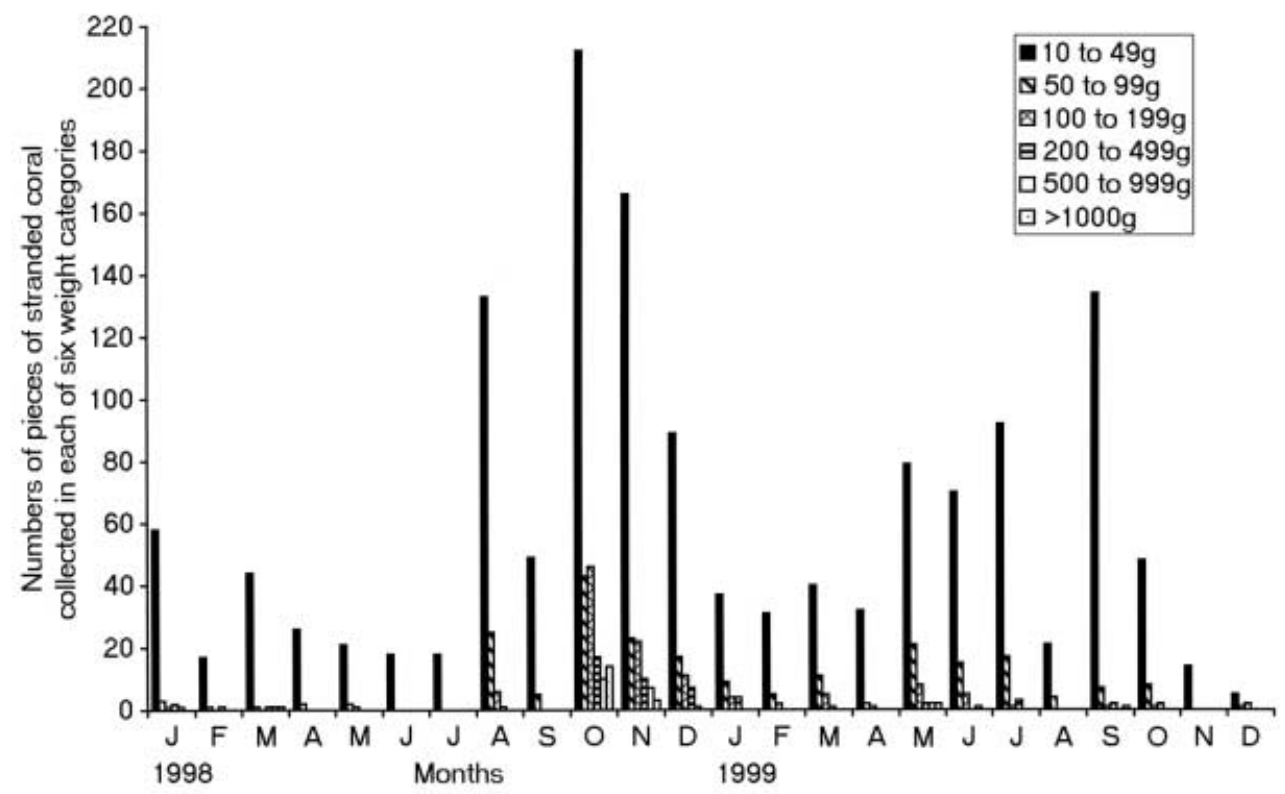

Figure 8. The numbers of all pieces of coral collected each month from Telecom Bay over the period from 1 January 1998 to 31 December 1999 inclusive. The data are separated into six weight categories.

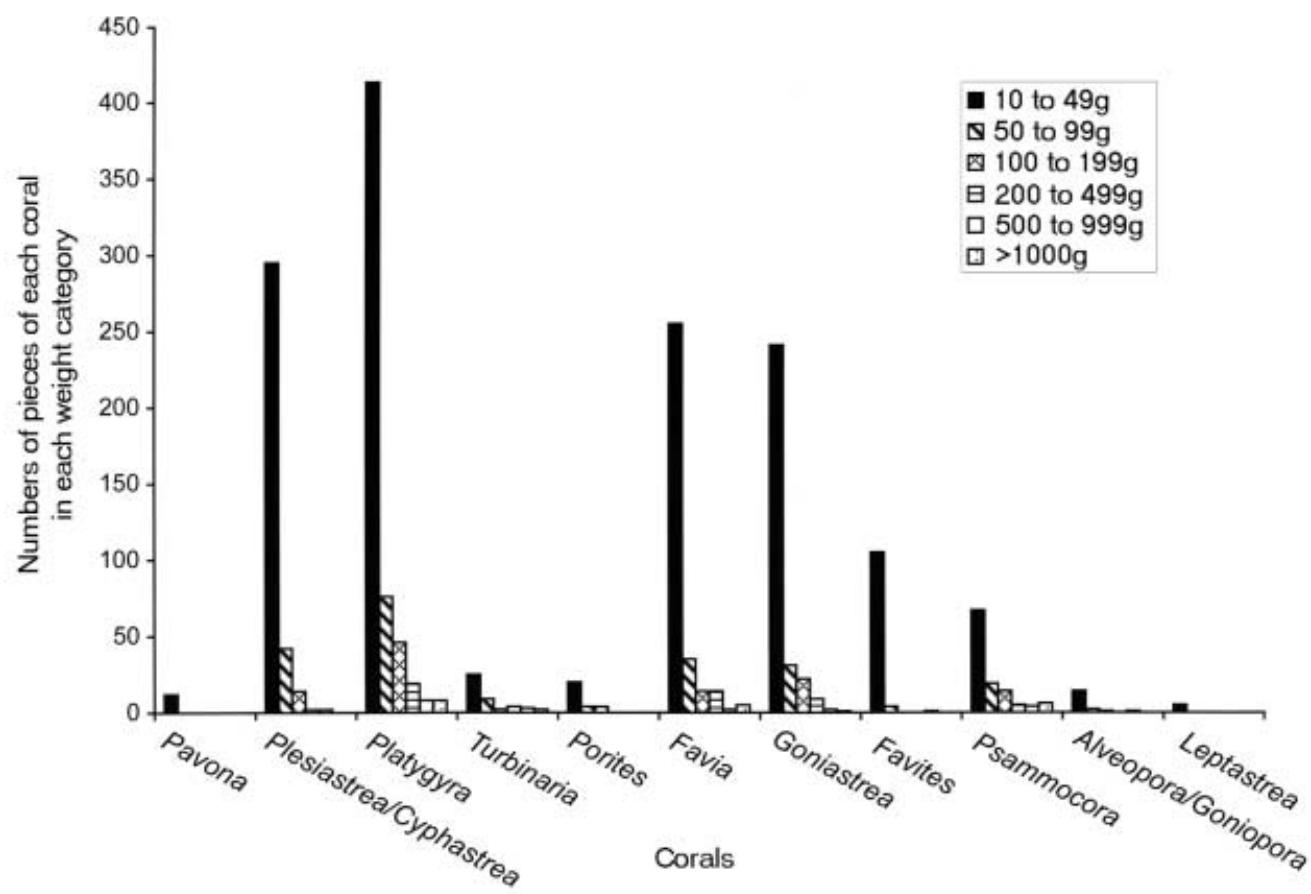

Figure 9. The total numbers of pieces of 11 corals collected from the shores of Telecom Bay, divided into six weight categories, over the total period of 24 months from 1 January 1998 to 31 December 1999.

\section{Numbers of pieces of corals in each weight category}

For the 24 months of 1998 and 1999, the overwhelming number of collected coral heads and pieces was in the category 10-49g, for example 133 in August 1998, 212 in October 1998, 166 in November 1998 and then declining to 32 in April 1999. Numbers in this category then rose (except for August 1999) to 134 in September 1999 but then fell to 48, 14 and 5 pieces in October, November and December 1999 (Figure 8), respectively. Numbers of coral pieces in the 50-99 g category were 25, 43 and 23 in August, October and November 1998, respectively. Thereafter, numbers fell to 2 in April 1999 but then rose to 21, 15 and 17 in May, June and July 1999, respectively. Numbers of coral pieces in the 100-199 g, 200-499 g, 500-999 $\mathrm{g}$ and $>1000$ g categories were nearly always very low except, notably, for October (46, 17, 10 and 14, respectively) and November 1998 (22, 10, 7 and 3, respectively).

Of the various species of corals identified (Figure 9), not unsurprisingly, the majority of pieces were in the 10-49 $\mathrm{g}$ weight category. This was especially noticeable for Platygyra (413), followed by Plesiastrea/Cyphastrea (295), Favia (255), Goniastrea (241), and Favites (105). Typically, $<50$ pieces of all other weight categories were collected over the 24 


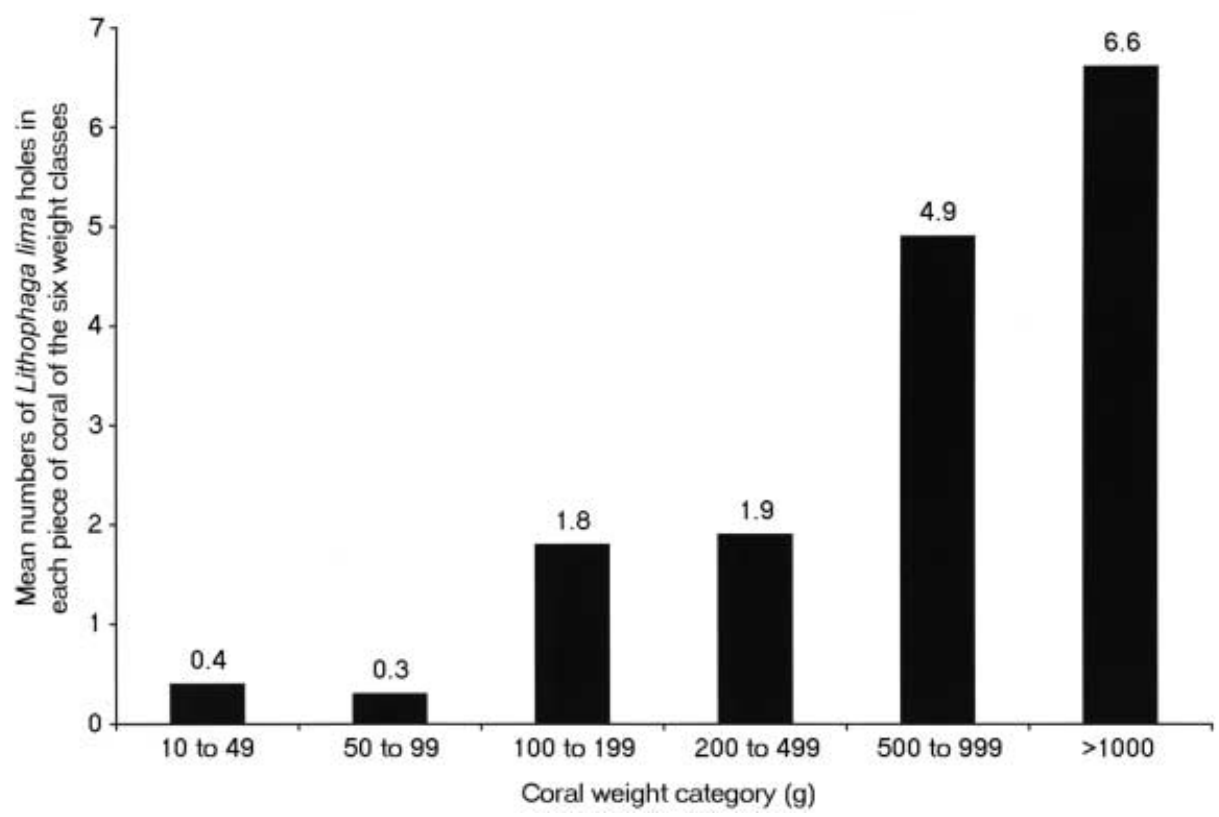

Figure 10. The mean number of Lithophaga lima holes per coral piece or head and for each of six weight categories recorded from the bases of the coral pieces collected from the shores of Telecom Bay over the total 24 months from 1 January 1998 to 31 December 1999 inclusive.
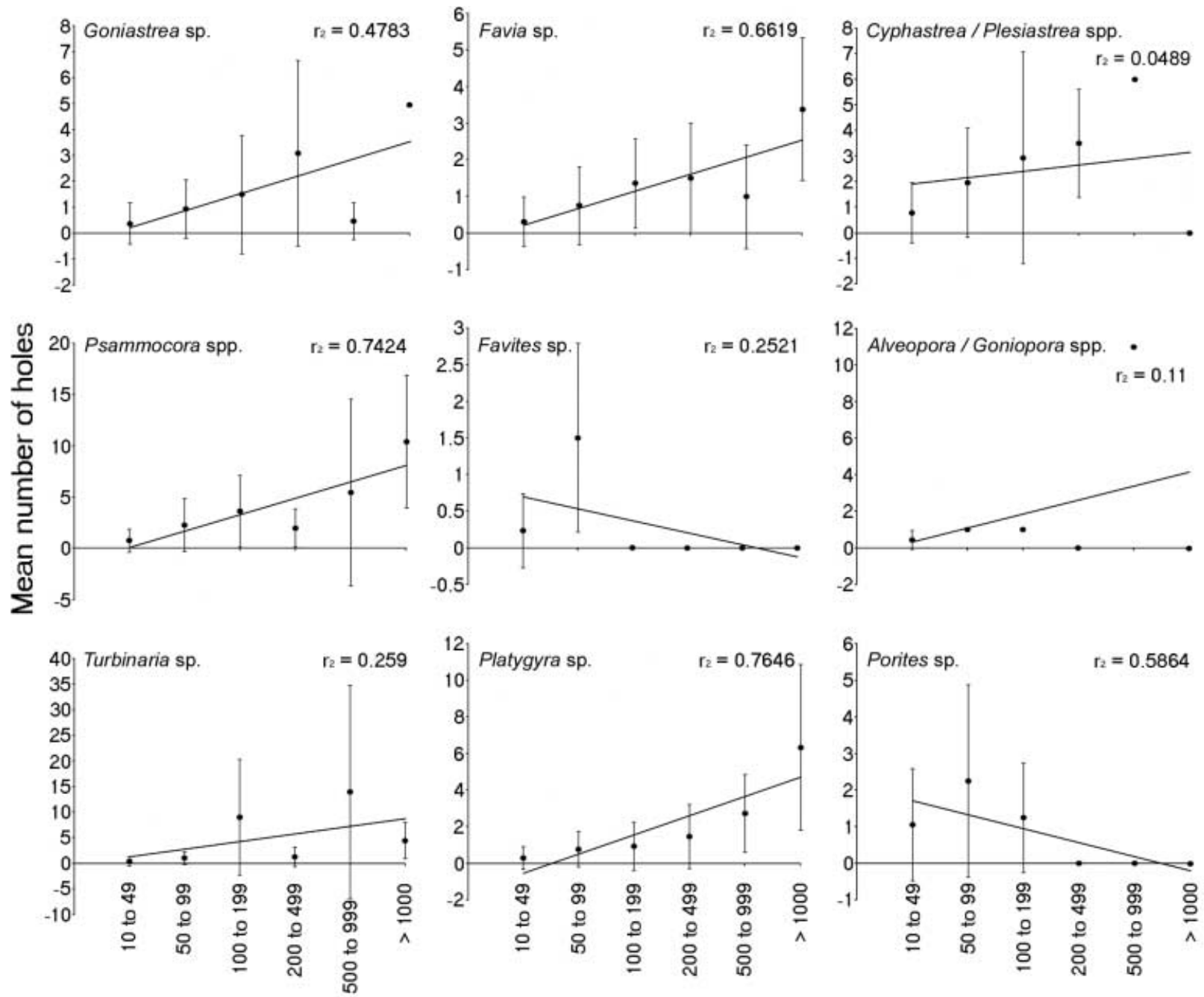

Weight $(\mathrm{g})$

Figure 11. The relationship between the mean numbers of Lithophaga lima boreholes in the bases of six size-categories of the nine commonest corals collected from the shores of Telecom Bay over a 24 month period from 1 January 1998 to 31 December 1999 inclusive. 
Table 3. Changes in the hierarchy of coral skeletons washing up on Telecom Bay Beach for 1996-1997 and 1998-1999.

\begin{tabular}{ll}
\hline 1996-1997 & $1998-1999$ \\
\hline Goniastrea & Platygyra \\
Plesiastrea/Cyphastrea & Plesiastrea/Cypastrea \\
Favia & Favia \\
Favites & Goniastrea \\
Psammocora & Psammocora \\
Porites & Favites \\
Turbinaria & Turbinaria \\
Platygyra & Porites \\
Alveopora/Goniopora & Alveopora/Goniopora \\
Leptoseris/Coscinarea & Pavona \\
Pavona & Leptoseris/Coscinarea \\
\hline
\end{tabular}

month period (including added post-typhoon collections), for example, 50-99 g (Platygyra, 76; Plesiastrea/Cyphastrea, 42; Favia, 35; Goniastrea, 31), 100-199 g (Platygyra, 46; Goniastrea, 22; Plesiastrea/Cyphastrea, Favia and Psammocora, 14), 200$499 \mathrm{~g}$ (Platygyra, 19; Favia, 14) 500-999 g (Platygyra, 8) and $>1000 \mathrm{~g}$ (Platygyra, 8; Psammocora, 6; Goniastrea, 5).

\section{Numbers of Lithophaga holes}

The mean numbers of Lithophaga holes in the bases of all the coral species combined ranged from between 0.4-0.3 in the 10-49 $\mathrm{g}$ and $50-99 \mathrm{~g}$ weight categories to 6.6 in the $>1000 \mathrm{~g}$ category (Figure 10). This generalized picture is broken down into coral genera in Figure 11 and all, except Favites and Porites, show the same general trend, i.e. more holes in the bases of larger heads as opposed to smaller pieces. The above two exceptions to the generalization, moreover, are because only small pieces $(10-199 \mathrm{~g})$ of these species were ever collected. The significance of this, however, is that pieces of corals in each weight category, regardless of species, do have the same number of boreholes and so stand an equal chance of being dislodged. Beached specimens are thus representative of what is in the sea in front of Telecom Bay.

\section{DISCUSSION}

The rainfall at Cape d'Aguilar in July 1997 was 602 mm, almost five times more than in 1996 and total rainfall for the year was $53 \%$ more than normal. The average July 1997 figure of total rainfall for Hong Kong ( 746 mm) was also more than double the normal average for the month (Table 1). August 1997 was another month with higher than normal rainfall and at $829 \mathrm{~mm}$ was the fourth highest total ever recorded for the month. The accumulated rainfall for June, July and August 1997 was 2359 mm, i.e. about twice as much as occurs in a normal year, and the highest ever recorded for these three months. In addition, the accumulated rainfall since 1 January was $2984 \mathrm{~mm}$ and the highest ever recorded for the period (Hong Kong Observatory, 1997). Such high levels of rainfall affected surface water salinities not only at Cape d'Aguilar (Figure 1) but throughout Hong Kong.
Monitoring data from the eastern waters of Hong Kong during July 1997 did not show anomalies in sea surface temperature but all showed a significant fall in salinity at $1 \mathrm{~m}$ below the surface (Environmental Protection Department, 1998). Nowhere, however, did bottom (1 m above the seabed) salinity values exhibit anomalies, i.e. all changes were surficial and thus related to rainfall and run-off. In association with the record levels of rainfall in July and August 1997, a massive bleaching event occurred throughout the waters of Hong Kong in the summer and was particularly associated with the hyposaline conditions recorded from shallow inshore areas over a period of 4-6 weeks. Ms D. McCorry (personal communication) has shown that during this period and throughout Hong Kong's eastern and southern waters, 35 species of Scleractinia exhibited bleaching as a result of hypo-osmotic stress with an average colony response of $\sim 25 \%$ of the surface area of each head. Pavona decussata showed the highest bleaching occurrence $(100 \%)$ followed by Goniopora columna and Montipora informis (75-100\%). Montipora informis and Acropora pruinosa were the only species to suffer total colony mortality. Pavona decussata suffered high levels of partial mortality while all other species were observed to recover within 4-8 weeks of ambient salinity returning to normal values (by mid-September 1997).

Cape d'Aguilar is little-influenced by significant sources of freshwater, there being only temporary streams and runoff on this remote headland. The sea is virtually always oceanic (Morton \& Harper, 1995). Notwithstanding, in June and July 1997, through simple runoff, the salinity in Telecom Bay fell to at least as low as 13 psu (Figure 1).

Clark (2000) showed that since 1995 and 1997, there had been a significant reduction in both individual colony numbers and percentage cover by scleractinian corals within the marine reserve, as well as a reduction in coral species richness and diversity. In 1998, Clark, (2000) recorded a total of 11 coral species, belonging to 11 genera and five families, i.e. a (statistical) decrease by four species, four genera and three families since 1997, albeit with the Faviidae still dominant. At Clark's sites B and E the dominant species had changed from Favites abdita at site E to Goniastrea aspera at them both. Within the reserve, there was a notional loss of six previously recorded species, i.e. Acropora pruinosa, Montipora informis, Coscinaraea columna, Turbinaria peltata, Oulastrea crispata and Hydnophora exesa, although two new species were recorded, i.e. Goniopora columna and Lithophyllon edwardsi. The overall recorded decline in the coral community may be attributed to extreme low salinity levels during the summer of 1997 and at Clark's site D to a large increase in sediment input during the latter period of 1996 and which may have contributed to the specific demise of the corals here (Clark, 2000).

Wave exposure is also high at Cape d'Aguilar especially during the summer period when typhoons are more prevalent and Clark (1997) has shown that unless coral heads transplanted to such wave-exposed areas are secured by embedding in concrete, less secure means cause their demise. Wave action also increases sediment levels in these shallow bays through bottom stirring. The conditions of the marine reserve can, therefore, only support the most tolerant species (Clark, 2000). Between 1996-1997, the largest numbers of coral heads and pieces washing up on the shores of Telecom Bay were Goniastrea aspera (Clark 
\& Morton, 2000). Between 1998-1999, after the above changes, however, although $G$. aspera colonies were still washed up, they were now of lesser importance to Platygyra sinensis - the coral that Clark (2000) suggested had suffered the most mortality over the same period (Table 3 ). Living $G$. aspera seemed to have survived the natural perturbations and was, thus, less-well-represented on the beach.

Clark \& Morton (2000) collected huge amounts of coral from Telecom Beach in 1996 and 1997 after severe tropical storms or typhoons (Typhoon Sally, 25,000 g: Typhoon Victor, $60,000 \mathrm{~g}$ ) and attributed this to such natural perturbations. In 1998 too, amounts of coral increased after the passage of a severe tropical storm (no-name) on 10 August. In October, a large coral head of 43,190 $\mathrm{g}$ also increased the total amount of coral on the beach (Table 2). Thereafter, however, amounts collected were small and in 1999 when seven tropical storms, severe tropical storms or typhoons either passed close to or over Hong Kong, there were usually increases in the numbers and weights of coral pieces deposited on the beach (Figure $7 \mathrm{~A}-\mathrm{G}$ ), but these were minor compared to 1996 and 1997 (Clark \& Morton, 2000; figure 5) (Table 2). Considering also the frequency of the events, especially in 1999, the post-typhoon coral weights collected after them are miniscule (Figure 6).

Table 2 summarizes the coral collection data for the four years. On the normal sampling days in January 1996, 1997, 1998 and 1999, totals of 38,000 g, $4000 \mathrm{~g}, 2500 \mathrm{~g}$ and $2980 \mathrm{~g}$ of corals were collected, respectively. That is, there was a general, but declining, input onto the beach, despite it being cleaned each month for four years. But, in 1999, the total of seven severe tropical storm or typhoon events collectively only dumped 28,175 g of mostly small (Figures 8 \& 9) coral pieces onto the beach. This must be compared with the 25,000 g, 60,000 $\mathrm{g}$ and 79,240 g, dumped onto it after four typhoon events in 1996, 1997 and 1998, i.e. a total of $164,240 \mathrm{~g}$.

The change in dominance between 1995 and 1998, particularly at site D in Telecom Bay, among the living coral species, from Platygyra to Goniastrea (Clark, 2000) was reflected in the changed incidence of these species collected from the beach subsequently (Table 3), with the formerly dominant Platygyra in Telecom Bay in 1996/1997 killed by the severe hyposalinity event of 1997, being washed up on the beach as dead heads and pieces in 1998-1999. Conversely, the less dominant Goniastrea in Telecom Bay in 1996-1997 was washed up in lesser numbers in 1998-1999 because dislodging effects seemed to have declined in the intervening time. The other nine common coral genera in the bay occupied similar positions in the beaching abundance hierarchy between 1996-1997 and 1998-1999. In 1999, however, the seven severe tropical storms and typhoons apparently had little affect on Telecom Bay corals and although the numbers of beached pieces did increase after each event, weights were minor and few significant moribund coral heads were collected unlike in 1996 and 1997.

Cumming \& McCorry (1998) suggested that an outbreak of the corallivorous muricid Drupella rugosa was devasting Hong Kong's corals. Morton \& Blackmore (2000), however, showed that such aggregations were natural and effects upon local corals minimal. Clark (1995) noted that Porites lobata had died in a coral pool in Cape d'Aguilar for unknown reasons. Zou et al. (1992) recorded that corals had died in Hoi Ha Wan as a result of sediment run-off from the Tai Leng Tun borrow area for the Ma On Shan New Town reclamation in Tolo Harbour. It thus seems that natural perturbations, such as heavy rainfall do have profound effects upon Hong Kong's corals because of reduced surface salinities (Zou et al., 1992; Clark, 2000). Rainfall may also wash terrigenous sediments into inshore waters, as at Hoi Ha Wan and Cape d'Aguilar, following construction work, exacerbating salinity effects. Because rainfall is typically heavier in summer, released coral gametes suffer intense mortality making local recruitment difficult (Collinson, 1997). Hong Kong's corals are thus stressed by low temperatures in winter and by natural heavy rainfall events in summer.

Hong Kong's corals were collected, until the 1950s, for lime production (Morton \& Ruxton, 1992) and subsequently have been subjected to all manner of pollution perturbations most well-documented for Tolo Harbour (Scott \& Cope, 1982, 1990; McCorry \& Blackmore, 2000). There is also extensive dynamiting (Morton, 1990; Cornish \& McKellar, 1998) and all manner of other perturbations (McCorry \& Cumming, 1999).

In 1995, however, Hong Kong's Marine Parks Ordinance was passed by the Legislative Council and in 1996, Cape d'Aguilar, including Telecom Bay, was declared the first (and still only) local marine reserve (Morton, 1998). The reserve is tiny (Morton \& Harper, 1995), i.e. but 18 hectares of water. It is also shallow and so cannot be trawled, but it can be gill-netted leading, as elsewhere in Hong Kong, to problems with ghost nets. Fishermen try to retrieve nets snagged on corals initially by pulling them and, in so doing, dislodge the heads of, particularly, shallow species. All fishing was banned in the Cape d'Aguilar Marine Reserve in 1996, nets were removed and the law enforced in 1997. In 1998 and 1999, unlike 1996 and 1997, few coral heads were beached in Telecom Bay even after seven significant storms. Is there a correlation?

Some reports, e.g. Ogg \& Koslow (1978), suggest that typhoons have a powerfully destructive impact upon shallow corals, whereas others, e.g. Sudara et al. (1992) conclude that they only have a limited effect. For example, when Typhoon Gay passed over the Gulf of Thailand in 1989, damage was restricted to certain areas while destruction in others was localized. This patchy effect was also reported upon by Done (1992) with respect to Tropical Cyclone Ivor passing over the Great Barrier Reef in March 1990. This led Massel \& Done (1993) to suggest that waves are important as controls on colony-size frequency distributions only for either weakly or unattached colonies, and as experimentally shown for Cape d'Aguilar by Clark (1997). Hurricane Pauline, the first documented strike on an eastern Pacific reef, caused only slight damage (Glynn et al., 1998). This study suggests this too, at least for 1999, and it is thus suspected that only where coral reefs are perturbated by physical damage, as on the Great Barrier Reef (Done, 1992), and here in Hong Kong, are storm waves problematic.

Generally speaking, tugged entangled nets and typhoons have the same effects upon corals - they may dislodge them and the latter, through wave action, can then beach them, as suggested by Clark \& Morton (2000) for Telecom Bay during 1996 and 1997. The ease of dislodgement will 
be facilitated by the weakening of basal attachment by coral borers notably species of Lithophaga in general (Hutchings, 1986) and, particularly, in Hong Kong, L. lima with the widest spectrum of corals bored (Scott, 1980; Morton \& Scott, 1980). This study shows that, in general, for the nine commonest species of corals in the bay and those beached on Telecom Bay, the numbers of Lithophaga boreholes in the coral bases showed a positive relationship with colony size. Larger pieces of all corals could, therefore, be thought of as being potentially more weakly attached and because of their size more likely to be snagged by fishing nets. Very rarely, unlike 1996 and 1997 (Clark \& Morton, 2000), however, were large coral heads stranded during 1998 and 1999 despite both being typhoon years, the latter experiencing seven storms! The conclusion must be, therefore, that today, especially, large coral heads are not being dislodged and dumped on Telecom Bay beach, even after typhoons.

An exception to the above argument, however, was October 1998 when Typhoon Babs did cause a large deposition of coral heads on the beach. Unusually, however, Typhoon Babs had prevailing winds from the south-west, all others in 1998 and 1991 being generally northerly (Table 2) and so wave action associated with this typhoon was directly over the Telecom Bay corals and towards Telecom Beach. Possibly, therefore, local wind direction can influence the amounts of corals beached. Significantly, Done (1992) also believed that local wind-generated waves may be the cause of coral destruction, not prevailing ocean swells. More significantly, however, wind directions in Hong Kong in 1996 and 1997 were also from the northern quarter but still dumped huge numbers of corals into Telecom Beach, but did not in 1999. The conclusion of this study, therefore, is that designation of marine reserve status has halted gill net and purse seine fishing in the Cape d'Aguilar Marine Reserve and corals have now largely stopped being dislodged as a result of net retrieval and hence are no longer deposited on Telecom Bay Beach, even by typhoons.

I am grateful to Manna Wan, particularly with regard to data analysis and production of the figures.

\section{REFERENCES}

Apps, R.F. \& Chen, T.Y., 1973. Sea waves at Waglan Island, Hong Kong. Royal Observatory, Hong Kong. Technical Note, no. 36, pp. 1-18, figures 1-35.

Blair, S.M., McIntosh, T.L. \& Mostkoff, B.J., 1994. Impacts of Hurricane Andrew on the offshore reef systems of central and northern Dade County, Florida. Bulletin of Marine Science, 54, 961-973.

Bradbury, R.H. \& Young, P.C., 1981. The effects of a major forcing function, wave energy, on a coral reef ecosystem. Marine Ecology Progress Series, 5, 229-241.

Clark, T., 1995. Hong Kong marine reserve comes too late to save corals. Marine Pollution Bulletin, 30, 770-771.

Clark, T., 1997. Tissue regeneration rate of coral transplants in a wave exposed environment, Cape d'Aguilar, Hong Kong. In Proceedings of the Eighth International Coral Reef Symposium, 2, 2069-2074.

Clark, T., 1998. The distribution of hermatypic scleractinian corals at Cape d'Aguilar, Hong Kong. In The marine biology of the South China Sea III. Proceedings of the Third International Conference on the Marine Biology of the South China Sea, Hong Kong 1996 (ed. B. Morton), pp. 151-164. Hong Kong: Hong Kong University Press.
Clark, T., 2000. A re-survey of the coral communities in the Cape d'Aguilar Marine Reserve, Hong Kong. In The marine flora and fauna of Hong Kong and southern China V. Proceedings of the Tenth International Marine Biological Workshop: The Marine Flora and Fauna of Hong Kong and Southern China, Hong Kong 1998 (ed. B. Morton), pp. 319-330. Hong Kong: Hong Kong University Press.

Clark, T. \& Morton, B., 1999. Relative roles of bioerosion and typhoon-induced disturbance on the dynamics of a high latitude scleractinian coral community. Fournal of the Marine Biological Association of the United Kingdom, 79, 803-820.

Collinson, P.R.J., 1997. The ecology of a peripheral, subtropical coral community in Hong Kong. PhD thesis, University of Hong Kong.

Cope, M. \& Morton, B., 1988. The scleractinian coral community at Hoi Ha Wan, Hong Kong. Asian Marine Biology, 5, 41-52.

Cornish, A.S. \& McKellar, D., 1998. Fishing with explosives and poisons in Hong Kong, China: history and legislation. In Proceedings of the APEC Workshops on the Impacts of Destructive Fishing Practices on the Marine Environment, Hong Kong 1997, pp. 82-88. Hong Kong, China: Agriculture \& Fisheries Department.

Cumming, R.L. \& McCorry, D., 1998. Corallivorous gastropods in Hong Kong. Coral Reefs, 17, 178.

Dollar, S.J., 1982. Wave stress and coral community structure in Hawaii. Coral Reefs, 1, 71-81.

Done, T.J., 1992. Effects of tropical cyclone waves on ecological and geomorphological structures on the Great Barrier Reef. Continental Shelf Research, 12, 859-872.

Environmental Protection Department, 1998. Environment Hong Kong 1998. Hong Kong SAR Government: Environmental Protection Department.

Fenner, D.P., 1991. Effects of Hurricane Gilbert on coral reefs, fishes and sponges at Cozumel, Mexico. Bulletin of Marine Science, 48, 719-730.

Freeland, H.J., Peterson, W.T. \& Tyler, A. (conveners). 1999. Proceedings of the 1998 Science Board Symposium on the impacts of the 1997/98 El Niño event on the North Pacific Ocean and its marginal seas, no. $10,131 \mathrm{pp}$.

Glynn, P.W., Almolovar, L.R. \& Gonzalez, J.G., 1964. Effects of Hurricane Edith on marine life in La Parguera, Puerto Rico. Caribbean Fournal of Science, 4, 335-345.

Glynn, P.W., Lirman, D., Baker, A.C. \& Leyte Morales, G.E., 1998. First documented hurricane strikes on eastern Pacific coral reefs reveal only slight damage. Coral Reefs, 17, 368.

Hernandez-Avila, M., Roberts, H. \& Rouse, L., 1977. Hurricane generated waves and coastal boulder rampart formation. Proceedings of the Third International Coral Reef Symposium, Miami, Florida, 1977, 2, 71-78.

Highsmith, R.C., 1980. Geographic patterns of coral bioerosion: a productivity hypothesis. Fournal of Experimental Marine Biology and Ecology, 46, 177-196.

Hong Kong Observatory, Hong Kong. 1996. Summary of meteorological observations in Hong Kong 1996. Hong Kong: Hong Kong Government.

Hong Kong Observatory, Hong Kong. 1997. Summary of meteorological observations in Hong Kong 1997. Hong Kong: Hong Kong Government.

Hong Kong Observatory, Hong Kong. 1998. Summary of meteorological observations in Hong Kong 1998. Hong Kong: Hong Kong SAR Government.

Hong Kong Observatory, Hong Kong. 1999. Summary of meteorological observations in Hong Kong 1999. Hong Kong: Hong Kong SAR Government.

Hutchings, P.A., 1986. Biological destruction of coral reefs. Coral Reefs, 4, 239-252.

Maragos, J.E., Barnes, G. \& Beveridge, P., 1973. Tropical cyclone Bebe creates a new land formation on Funafuti Atoll. Science, New York, 181, 1161-1164. 
Massel, S.R. \& Done, T.J., 1993. Effects of cyclone waves on massive coral assemblages on the Great Barrier Reef: meteorology, hydrodynamics and demography. Coral Reefs, 12, 153-166.

McCorry, D. \& Blackmore, B., 2000. Tolo revisited: a resurvey of the corals and their metal burdens in Tolo Harbour and Channel twelve years and one million people later. In The marine flora and fauna of Hong Kong and southern China $V$. Proceedings of the Tenth International Marine Biological Workshop: The Marine Flora and Fauna of Hong Kong and Southern China, Hong Kong 1998 (ed. B. Morton), pp.455-484. Hong Kong: Hong Kong University Press.

McCorry, D. \& Cumming, R.L., 1999. Hong Kong's coral communities: surviving adversity. Coral Reefs, 18, 408.

Morton, B., 1990. Booming Hong Kong. Marine Pollution Bulletin, 21, 165-166.

Morton, B., 1998. Hong Kong's Marine Parks Ordinance and designation of the first marine parks and reserve: where next? In The marine biology of the South China Sea. Proceedings of the Third International Conference on the Marine Biology of the South China Sea, Hong Kong 1996 (ed. B. Morton), pp.541-561. Hong Kong: Hong Kong University Press.

Morton, B. \& Blackmore, G., 2000. The impacts of an outbreak of corallivorous gastropods, Drupella rugosa and Cronia margariticola (Muricidae), on Hong Kong's scleractinian corals. Hong Kong: The Swire Institute of Marine Science, The University of Hong Kong.

Morton, B. \& Harper, E., 1995. An introduction to the Cape d'Aguilar Marine Reserve, Hong Kong. Hong Kong: Hong Kong University Press.

Morton, B. \& Morton, J., 1983. The sea shore ecology of Hong Kong. Hong Kong: Hong Kong University Press.

Morton, B. \& Ruxton, J., 1992. Hoi Ha Wan. Hong Kong: World Wide Fund for Nature.

Morton, B. \& Scott, P.J.B., 1980. Morphological and functional specializations of the shell, musculature and pallial glands in the Lithophaginae (Mollusca: Bivalvia). Journal of Zoology, 192, 179-203.

Ogg, J.G. \& Koslow, J.A., 1978. The impact of Typhoon Pamela (1976) on Guam's coral reefs and beaches. Pacific Science, 32, 105-118.

Rogers, G.S., Mclain, L.N. \& Craig, R.T., 1991. Effects of Hurricane Hugo (1989) on a coral reef in St John, USVI. Marine Ecology Progress Series, 78, 189-199.

Rogers, C.S., Suchanek, T.H. \& Pecera, F.A., 1982. Effects of Hurricane David and Frederic (1979) on shallow Acropora palmata reef communities: St. Croix, U.S. Virgin Islands. Bulletin of Marine Science, 32, 532-548.
Scott, P.J.B., 1980. Associations between scleractinians and coralboring molluscs in Hong Kong. In The Malacofauna of Hong Kong and southern China. Proceedings of the First International Workshop on the Malacofauna of Hong Kong and Southern China, Hong Kong 1977 (ed. B. Morton), pp.121-137. Hong Kong: Hong Kong University Press.

Scott, P.J.B. \& Cope, M., 1982. The distribution of scleractinian corals at six sites within Tolo Harbour and channel. In The marine flora and fauna of Hong Kong and southern China. Proceedings of the First International Marine Biological Workshop: The Marine Flora and Fauna of Hong Kong and Southern China, Hong Kong 1980 (ed. B. Morton and C.K. Tseng), pp. 574-585. Hong Kong: Hong Kong University Press.

Scott, P.J.B. \& Cope, M., 1990. Tolo revisited: a survey of the corals in Tolo Harbour and Channel six years and half a million people later. In The marine flora and fauna of Hong Kong and southern China II. Proceedings of the Second International Marine Biological Workshop: The Marine Flora and Fauna of Hong Kong and Southern China, Hong Kong 1986 (ed. B. Morton), pp. 1203-1220. Hong Kong: Hong Kong University Press.

Stoddart, D.R., 1974. Post-hurricane changes on the British Honduras reefs: resurvey of 1972. Proceedings of the Second International Coral Reef Symposium, Townsville, Australia, 1988, 2, 473-483.

Sudara, S., Yeemin, T., Nateekarnjanalarp, S., Satumanatpan, S., Chamapan, A. \& Amornsakchai, S., 1992. The impact of Typhoon Gay on coral communities of Tao Island, Gulf of Thailand. In Third ASEAN Science and Technology Week Conference Proceedings. Vol. 6. Marine science: living coastal resources. Singapore: National University of Singapore and National Science and Technology Board.

Woodley, J.D. et al., 1981. Hurricane Allen's impact on Jamaican corals reefs. Science, New Tork, 214, 749-755.

Zou, R.L., Wang, Z.H. \& Cheung, C.P.S., 1992. A resurvey of the corals at Hoi Ha Wan after eight years and the Tai Leng Tun borrow area. In The marine flora and fauna of Hong Kong and southern China III. Proceedings of the Fourth International Marine Biological Workshop: The Marine Flora and Fauna of Hong Kong and Southern China, Hong Kong 1989 (ed. B. Morton), pp. 837-849. Hong Kong: Hong Kong University Press.

Submitted 29 November 2001. Accepted 15 July 2002. 